ORIGINAL ARTICLE

\title{
Non-invasive ventilation in acute respiratory failure: a randomised comparison of continuous positive airway pressure and bi-level positive airway pressure
}

\author{
A M Cross, P Cameron, M Kierce, M Ragg, A-M Kelly
}

Emerg Med J 2003;20:531-534

See end of article for authors' affiliations

Correspondence to:

Anthony Cross, 29 Stawell

Street, Kew, Victoria

3101, Australia;

antdom@bluep.com

Accepted for publication

7 January 2003

\begin{abstract}
Objectives: To determine whether there is a difference in required duration of non-invasive ventilation between continuous positive airway pressure (CPAP) and bi-level positive airway pressure (BiPAP) in the treatment of a heterogeneous group of emergency department (ED) patients suffering acute respiratory failure and the subgroup of patients with acute pulmonary oedema (APO). Secondary objectives were to compare complications, failure rate, disposition, length of stay parameters, and mortality between the treatments.

Methods: This prospective randomised trial was conducted in the emergency departments of three Australian teaching hospitals. Patients in acute respiratory failure were randomly assigned to receive CPAP or BiPAP in addition to standard therapy. Duration of non-invasive ventilation, complications, failure rate, disposition, length of stay (hospital and ICU), and mortality were measured.

Results: 101 patients were enrolled in the study (CPAP 51, BiPAP 50). The median duration of noninvasive ventilation with CPAP was 123 minutes (range 10-338) and 132 minutes (range 20-550) for $\operatorname{BiPAP}(p=0.206$, Mann-Whitney). For the subgroup suffering APO, 36 were randomised to CPAP and 35 to BiPAP. For this group the median duration of non-invasive ventilation for CPAP was 123 minutes (range 35-338) and 133 minutes (range 30-550) for BiPAP ( $p=0.320$, Mann-Whitney).

Conclusions: These results suggest that there is no significant difference in the duration of non-invasive ventilation treatment between CPAP and BiPAP when used for the treatment of acute respiratory failure in the ED. There was also no significant difference between the groups in secondary end points.
\end{abstract}

Abbreviations: CPAP, continuous positive airway pressure; BiPAP, bilevel positive airway pressure; APO, acute pulmonary oedema; NIV, non-invasive ventilation; COAD, chronic obstructive airways disease; PEEP, positive end respiratory pressure

\section{METHODS}

This prospective, randomised study was conducted in the emergency departments of three Australian teaching hospitals: The Royal Melbourne Hospital, Geelong Hospital, and Western Hospital. The study was approved by the relevant clinical research and ethics committees.

Patients presenting to the ED in acute respiratory failure deemed by the treating clinician to require NIV support were randomly assigned to receive either CPAP or BiPAP in addition to standard medical treatment. For the purposes of this study acute respiratory failure was defined by any one of the following inclusion criteria: $\mathrm{SaO}_{2}<90 \%$ on air, $\mathrm{SaO}_{2}<93 \%$ on $>6$ litres $\mathrm{O}_{2} / \mathrm{min}$, inability to speak in sentences or respiratory rate $>25 / \mathrm{min}$. These criteria were selected to reflect current practice; enabling rapid clinical assessment and initiation of treatment before arterial blood gas analysis has been performed and to include what has traditionally been defined as type 1 and 2 respiratory failure.

Exclusion criteria were: obtundation (to the point of being unable to cooperate or protect the airway), traumatic and congenital causes of respiratory failure (for example, cystic fibrosis, Duchenne's muscular dystrophy), pneumothorax, gross radiological lobar pneumonia, endotracheal intubation, and a decision to withhold or withdraw treatment made by the clinician in consultation with the patient and/or next of kin. inspiration. Until now this has not been tested by clinical comparison.

The aim of this pilot study was to determine whether there was a difference between CPAP and BiPAP with respect to duration of NIV for patients with acute respiratory failure. Secondary objectives were to compare disposition and length of stay between the groups. 
Table 1 Levels of non-invasive ventilatory support

\begin{tabular}{lll}
\hline & CPAP $\left(\mathrm{cm} \mathrm{H}_{\mathbf{2}} \mathrm{O}\right)$ & $\begin{array}{l}\text { BiPAP-increasing PSV } \\
\left.\text { (EPAP/IPAP in } \mathbf{~ c m ~} \mathrm{H}_{\mathbf{2}} \mathrm{O}\right)\end{array}$ \\
\hline Initial level & 5 & $5 / 10$ \\
Second level & 10 & $5 / 15$ \\
Third level & 15 & $5 / 20$ \\
Fourth level & 20 & $5 / 25$ \\
\hline
\end{tabular}

For both groups NIV was started with a $\mathrm{FIO}_{2}$ of $70 \%$ at the initial level of ventilation within five minutes of arrival in the ED. The level of ventilatory support was increased in a stepwise fashion (table 1) every 5-15 minutes as clinically indicated. Optimal NIV was defined as the lowest pressure level of NIV and lowest $\mathrm{FIO}_{2}$ that maintained $\mathrm{SaO}_{2}>90 \%$ or $\mathrm{PaO}_{2}>60 \mathrm{~mm} \mathrm{Hg}$ without further deterioration of any clinical parameters. Weaning followed the reverse sequence and started once the patient had remained stable (by clinical and biochemical parameters) for 30 to 60 minutes.

If a patient randomised to CPAP treatment was diagnosed as having an acute exacerbation of COAD and was not improving after one to two hours of treatment the study protocol allowed for crossover to BiPAP. Such a crossover was considered a failure of CPAP.

Need for endotracheal intubation, and, thus, failure of NIV, were as previously described ${ }^{9}$ : respiratory arrest, respiratory pauses with loss of consciousness, psychomotor agitation (making nursing care impossible and requiring sedation), $\mathrm{HR}<50$ with loss of alertness and haemodynamic instability with systolic $\mathrm{BP}<70$. Additionally, the clinician could elect to intubate the patient if it is felt their condition was not improving satisfactorily or worsening. If intubation was required within 15 minutes of the start NIV this was judged to be an inappropriate application of NIV rather than a failure of treatment and these patients were excluded from analysis.

Standard treatment was defined according to the condition being treated. For acute pulmonary oedema; intravenous frusemide and nitrates (via any route, aiming for systolic blood pressure of 120-140 mm $\mathrm{Hg}$ and stopped if systolic blood pressure $<100 \mathrm{~mm} \mathrm{Hg}$ ). For acute exacerbations of asthma or COAD; $\beta$ agonists (initially continuous nebulised $0.5 \%$ salbutamol then, if required, intravenous infusions of adrenaline (epinephrine) $0.25-2.0 \mu \mathrm{g} / \mathrm{min}$ or salbutamol 5-
$20 \mu \mathrm{g} / \mathrm{min}$ ) and parenteral corticosteroids (hydrocortisone $250 \mathrm{mg}$ ). For pneumonia; ceftriaxone $1 \mathrm{~g}$ intravenously.

Data collected included age, sex, half hourly observations (HR, RR, BP, temperature, $\mathrm{SaO}_{2}$ and Glasgow coma score), blood gas pressures (on arrival, at one hour, and at two hourly intervals thereafter), complications, outcome of NIV (improved, worsened, or admitted with NIV continuing), whether further ventilatory support (standard or NIV) was needed during the admission, disposition (standard ward compared with coronary care, high dependency, or intensive care unit), hospital length of stay, ICU length of stay, and inhospital mortality.

The primary analysis included all patients on an "intention to treat" basis. This study was powered to detect a one hour difference in the duration of NIV. This time frame was selected as being the minimal reduction in treatment duration that would make a significant difference, from a practical point of view, in a busy ED. A subgroup analysis was conducted on the group of patients with APO.

Data were analysed using the two sample Wilcoxon rank sum (Mann-Whitney) test and Fisher's exact tests, as indicated.

\section{RESULTS}

Altogether 101 patients were enrolled in the study (CPAP 51, BiPAP 50). There were no significant differences in age, sex, vital signs, or arterial blood gas measurments on presentation between the groups (table 2).

Seventy one patients $(70 \%)$ were diagnosed as having had COAD $(21 \%)$, eight had pneumonia $(8 \%)$, and one had asthma $(1 \%)$.

The duration of NIV for the two modalities was not significantly different for either the overall group or the APO subgroup (table 3 ). In the overall group, the median duration of CPAP was 123 minutes (range 10-338) and, for BiPAP, 132 minutes (range 20-550) $(p=0.206)$. For the APO subgroup the median duration of CPAP was 123 minutes (range 35-338) and 133 minutes (range 30-550) for BiPAP $(\mathrm{p}=0.320)$

There was also no significant difference between the treatment modalities for the secondary end points in either the overall or APO groups (tables 3 and 4). None of the patients diagnosed with COAD and randomised to CPAP were crossed over to BiPAP.

\begin{tabular}{|c|c|c|c|c|c|c|c|c|c|c|}
\hline & \multicolumn{5}{|c|}{ Group overall $(n=101)$} & \multicolumn{5}{|c|}{ APO subgroup $(n=71)$} \\
\hline & \multicolumn{2}{|c|}{$\begin{array}{l}\text { A: CPAP } \\
(n=51, \\
50.5 \%)\end{array}$} & \multicolumn{2}{|c|}{$\begin{array}{l}\text { B: BiPAP } \\
\text { (n=50, 49.5\%) }\end{array}$} & \multirow[b]{2}{*}{ p Value } & \multicolumn{2}{|c|}{$\begin{array}{l}\text { A: CPAP } \\
\text { ( } n=36,35.6 \%)\end{array}$} & \multicolumn{2}{|c|}{$\begin{array}{l}\text { B: BiPAP } \\
\text { ( } n=35,34.7 \%)\end{array}$} & \multirow[b]{2}{*}{ p Value } \\
\hline & Mean & SD & Mean & SD & & Mean & SD & Mean & SD & \\
\hline Age (y) & 74 & 8 & 71 & 13 & 0.612 & 73 & 9 & 75 & 10 & 0.407 \\
\hline $\begin{array}{l}\text { Temperature } \\
\text { ( } \mathrm{C} \text { ) }\end{array}$ & 35.7 & 4.7 & 36.4 & 1.0 & 0.981 & 36.3 & 0.93 & 36.3 & 0.97 & 0.986 \\
\hline $\begin{array}{l}\text { Heart rate } \\
\text { (beat/min) }\end{array}$ & 114 & 23 & 119 & 24 & 0.635 & 111 & 25 & 119 & 23 & 0.112 \\
\hline $\begin{array}{l}\text { Systolic BP } \\
(\mathrm{mm} \mathrm{Hg})\end{array}$ & 162 & 35 & 148 & 30 & 0.090 & 162 & 34 & 151 & 30 & 0.285 \\
\hline $\begin{array}{l}\text { Diastolic BP } \\
\text { (mm Hg) }\end{array}$ & 87 & 28 & 86 & 20 & 0.825 & 90 & 28 & 87 & 21 & 0.922 \\
\hline $\begin{array}{l}\text { Respiratory rate } \\
\text { (min) }\end{array}$ & & 12 & 35 & 9 & 0.190 & 35 & 13 & 35 & 9 & 0.657 \\
\hline $\mathrm{SaO}_{2}(\%)$ & 92 & 8 & 90 & 13 & 0.911 & 91 & 8 & 89 & 14 & 0.822 \\
\hline GCS & 14 & 2 & 14 & 2 & 0.387 & 14 & 2 & 14 & 2 & 0.312 \\
\hline pH & 7.22 & 0.10 & 7.25 & 0.11 & 0.189 & 7.22 & 0.11 & 7.24 & 0.11 & 0.411 \\
\hline
\end{tabular}




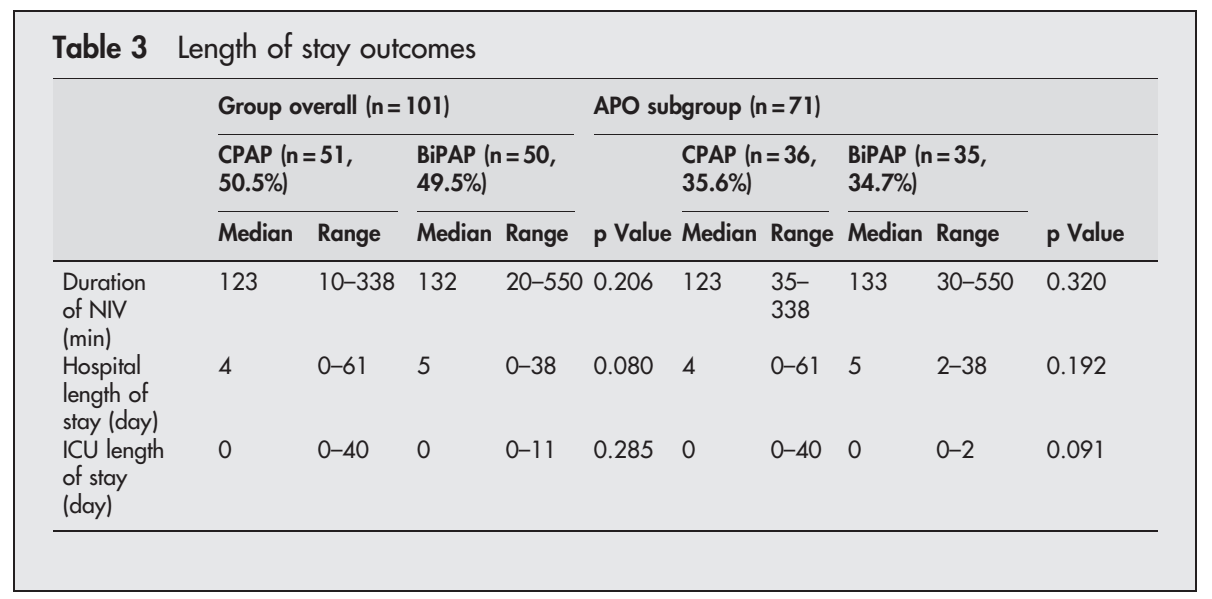

The overall complication rate in this study was $8 \%$. The complication rate was not significantly different for CPAP compared with BiPAP in either the heterogenous or the APO group $(p=1.00$ for both). Of the eight patients with complications two had vomiting, three had respiratory deterioration, one cardiogenic shock, one hypotension, and one evolution of ST segment elevation on the ECG.

\section{DISCUSSION}

Emergency physicians are often confronted with patients with acute respiratory failure. On occasion it is necessary to select therapeutic interventions, including a method of NIV, before a firm diagnosis is made.

This study shows that CPAP and BiPAP are not significantly different with respect to duration of NIV, rates of complications, in-hospital mortality, disposition from the ED, hospital and ICU length of stay, or need for further ventilation in either the overall, heterogenous group, or the APO subgroup. These findings suggest that it is not important whether CPAP or BiPAP is given to patients with undifferentiated respiratory failure or those known to have APO.

An implication of this finding is that EDs considering acquisition of NIV equipment could potentially justify the purchase of a simpler, cheaper, CPAP only device with a low likelihood of compromising patient care.

The mean durations of NIV treatment compare very favourably with published experience. Mehta et al in a randomised trial in an ED setting comparing CPAP with BiPAP in acute pulmonary oedema reported mean durations of treatment of 6.4 hours (SD 5.8 hours) and 7.1 hours (SD 4.7 hours) respectively. ${ }^{7}$ Although many of the presentation characteristics of the patients and the ventilation levels in this study were similar there were two important differences: the use of nasal masks (the inability of distressed patients, unfamiliar with the device to maintain positive pressure in the airway is likely to have significantly reduced effectiveness) and the use of respiratory technicians to assess and adjust treatment would have been slower and less responsive than the bedside nurses who controlled treatment in this study. Kelly et al, in a retrospective study of CPAP for APO in an Australian ED, reported an average duration of treatment of 1.9 hours, ${ }^{11}$ very similar to this study. Most studies have been carried out in intensive care units with intermittent NIV over days to weeks. ${ }^{3-5}$ 8-10 1213

The rate of failure of NIV and need for endotracheal intubation was not significantly different between treatments for either the heterogenous or the APO group. The overall intubation rate of $9 \%$ compares favourably with the rates of $9 \%-24 \%$ quoted in the trials referred to above. It has been suggested there may be no means of predicting successful NIV (that is, avoidance of endotracheal intubation) on the basis of initial data. ${ }^{14}$

The obvious limitation to this study is the lack of an objective indicator as to when NIV should cease. Common practice relies on an ill defined mixture of the physician's clinical assessment of the patient, observations, blood gas analysis, and the timing of when the physician is able to review the patient. Although these factors apply equally to patients receiving CPAP and BiPAP the duration of treatment any individual patient actually needs may be shorter than has been found in this study. Another specific limitation was the inability to blind the treating staff to the mode of treatment because the ventilator's display indicates the modality. Other

\begin{tabular}{|c|c|c|c|c|c|c|c|c|c|c|}
\hline & \multicolumn{5}{|c|}{ Group overall $(n=101)$} & \multicolumn{5}{|c|}{ APO subgroup ( $n=71)$} \\
\hline & \multicolumn{2}{|c|}{$\begin{array}{l}\text { CPAP } \\
\text { (n=51, } \\
50.5 \%)\end{array}$} & \multicolumn{2}{|c|}{$\begin{array}{l}\text { BiPAP } \\
(n=50, \\
49.5 \%)\end{array}$} & \multirow[b]{2}{*}{$\mathrm{p}$ Value } & \multicolumn{2}{|c|}{$\begin{array}{l}\text { CPAP } \\
(\mathrm{n}=36, \\
35.6 \%)\end{array}$} & \multicolumn{2}{|c|}{$\begin{array}{l}\text { BiPAP } \\
(\mathrm{n}=35, \\
34.7 \%)\end{array}$} & \multirow[b]{2}{*}{$p$ Value } \\
\hline & $n$ & $\%$ & $\mathrm{n}$ & $\%$ & & $n$ & $\%$ & $\mathrm{n}$ & $\%$ & \\
\hline $\begin{array}{l}\text { Complications } \\
\text { ED NIV outcomes: }\end{array}$ & 4 & 8 & 4 & 8 & 1.00 & 3 & 8 & 1 & 3 & 1.00 \\
\hline Weaned & 44 & 86 & 45 & 90 & & 31 & 86 & 32 & 91 & \\
\hline Intubated & 6 & 12 & 3 & 6 & & 4 & 11 & 1 & 3 & \\
\hline Continued & 1 & 2 & 2 & 4 & 0.611 & 1 & 3 & 2 & 6 & 0.511 \\
\hline $\begin{array}{l}\text { Standard ward } \\
\text { disposition }\end{array}$ & 37 & 73 & 35 & 70 & 0.824 & 26 & 72 & 24 & 68 & 0.798 \\
\hline Further ventilation & 12 & 24 & 6 & 12 & 0.193 & 9 & 25 & 3 & 9 & 0.111 \\
\hline Hospital mortality & 9 & 18 & 7 & 14 & 0.786 & 5 & 14 & 3 & 9 & 0.710 \\
\hline
\end{tabular}


limitations relate to the generalisability of results to other hospitals.

No firm conclusions can be drawn from this study of the relative merits of CPAP and BiPAP in the emergency treatment of acute exacerbations of COAD, asthma, pneumonia, and a range of other specific causes of acute respiratory failure because low numbers in these subgroups precluded subgroup analysis.

In summary, this pilot study found there was little or no difference in duration of treament or outcomes for ED patients with acute respiratory failure of a heterogenous nature or for those with APO when CPAP was compared with BiPAP. No conclusions could be made when CPAP was compared with BiPAP in the setting of COAD.

\section{ACKNOWLEDGEMENTS}

Antony Ugoni, Department of General Practice and Public Health, University of Melbourne for statistical assistance in study design and data analysis. Medical and nursing staff in the emergency departments of the Royal Melbourne, Geelong, and Western Hospitals for their assistance in data collection, enrolling, and caring for the patients.

\section{Authors' affiliations}

A M Cross, The Royal Melbourne Hospital, Parkville, Victoria, Australia P Cameron, Emergency Department, The Royal Melbourne Hospital, Parkville, Victoria, Australia

M Kierce, School of Postgraduate Nursing, The University of Melbourne, Victoria, Australia

M Ragg, Emergency Department, The Geelong Hospital, Geelong,

Victoria, Australia

A-M Kelly, Joseph Epstein Centre for Emergency Medicine Research, Western Hospital, Footscray and The University of Melbourne, Victoria, Australia

Funding: none.
Conflicts of interest: none declared.

\section{REFERENCES}

1 Cross AM. Review of the role of non-invasive ventilation in the emergency department. J Accid Emerg Med 2000;17:79-85.

2 Kosowsky JM, Storrow AB, Carleton SC. Continuous and bilevel positive airway pressure in the treatment of acute cardiogenic pulmonary oedema. Am J Emerg Med 2000;18:91-5.

3 Räsänen J, Heikkilä J, Downs J, et al. Continuous positive airway pressure by face mask in acute cardiogenic pulmonary edema. Am J Cardiol 1985;55:296-300

4 Kramer N, Meyer TJ, Meharg J, et al. Randomised, prospective trial of Noninvasive positive pressure ventilation in acute respiratory failure. Am J Respir Crit Care Med 1995;151:1799-806.

5 Lin M, Yang YF, Chiang HT, et al. Reappraisal of continuous positive airway pressure therapy in acute cardiogenic pulmonary edema: short-term results and long-term follow-up. Chest 1995; 107:1379-86.

6 Wood KA, Lewis L, Von Harz B, et al. The use of noninvasive positive pressure ventilation in the emergency department; results of a randomized clinical trial. Chest 1998; 113:1339-46.

7 Mehta S, Jay GD, Woolard RH, et al. Randomized, prospective trial of bilevel versus continuous positive airway pressure in acute pulmonary edema. Crit Care Med 1997;25:620-8.

8 Bott J, Carroll MP, Conway JH, et al. Randomised controlled trial of nasal ventilation in acute ventilatory failure due to chronic obstructive airways disease. Lancet 1993;341:1555-7.

9 Brochard L, Mancebo J, Wysocki M, et al. Noninvasive ventilation for acute exacerbations of chronic obstructive pulmonary disease. N Engl J Med 1995;333:817-22.

10 Çelikel T, Sungur M, Ceyhan B, et al. Comparison of noninvasive positive pressure ventilation with standard medical therapy in hypercapnic acute respiratory failure. Chest 1998;114:1636-42.

11 Kelly AM, Georgakas C, Bau S, et al. Experience with the use of positive airway pressure (CPAP) therapy in the emergency management of acute severe cardiogenic pulmonary oedema. Aust N Z J Med 1997;27:319-22.

12 Bersten AD, Holt AW, Vedig AE, et al. Treatment of severe cardiogenic pulmonary edema with continuous positive airway pressure delivered by face mask. N Engl J Med 1991;325:1825-30.

13 Martin TJ, Hovis JD, Costantino JP, et al. A Randomised, prospective evaluation of noninvasive ventilation for acute respiratory failure. Am J Respir Crit Care Med 2000;161:807-13.

14 Poponick JM, Renston JP, Bennett RP, et al. Use of a ventilatory support system (BiPAP) for acute respiratory failure in the emergency department. Chest 1999; 116:166-71. 